\title{
Fostering collective effort toward ecosystem conservation
}

\author{
Elise Amel ${ }^{1, *}$, and Christie Manning ${ }^{2}$ \\ ${ }^{1}$ University of St. Thomas, Psychology Department, St. Paul, MN 55105 USA \\ ${ }^{2}$ Macalester College, Department of Environmental Studies, St. Paul, MN 55105 USA
}

\begin{abstract}
For human society to thrive amidst our changing environmental realities, we must alter our behavior. Individual change, while important, is unreliable due to cognitive and social barriers. An important nexus for the required transformation is at the collective level. Rather than encouraging individuals to engage in personal climate-friendly behavior, our efforts must focus on individuals changing their social networks, engaging in political change, and transforming the organizations in their community, such as corporations, NGOs, boards, and governments. Formal and informal leaders make daily decisions which influence the organizational structures that propel large-scale human behavior change. This scale of change is more in line with the scope needed to successfully persist into the future on this planet.
\end{abstract}

\section{Introduction}

When it comes to Climate Change, the environment is not the problem, human behavior is. And psychology has a role in understanding how we can make real progress to redirect it.

Scientists with clear insight into the causes and consequences of anthropogenic problems such as climate change insist that people must change; and while that is true [1] the challenge is that people do not "just change." There are real psychological and physical barriers that get in the way, particularly when it comes to an overwhelming, global crisis such as climate change. Emotions [2], worldview [3,4], cultural identity [5], and social pressures [6] are just a few examples of psychological factors that impact not only how we react to climate change, but also how we perceive it in the first place. Even after we have made a decision to act, numerous external constraints keep people from succeeding to change their behaviors in the face of large natural and human-built systems [7].

World-wide there is a groundswell of concern and action to address Climate Change. Even in the United States, where climate skepticism is a significant political wedge, the majority of citizens believe climate change is occurring (73\%)[8], believe it is humancaused (62\%)[8] are worried about its impact (69\%)[8], and believe that more action should be taken to deal with it [9]. Thus, a critical mass of individuals, particularly youth [10] are already engaging or are poised to engage in climate-friendly behavior.

Yet when encouraging people to take action to reduce their planetary impact, we tend to ask them to change their personal behaviors such as reducing single-occupancy driving, increasing recycling, purchasing energy efficient bulbs, and bringing reusable shopping bags to the store. This approach is problematic on many levels. For one, it goes against natural human tendencies; even under the best of circumstances, human beings struggle to move from knowledge to action. Second, individual efforts to change behavior require resisting or overriding enormous, complex systems. Third, acting within the sphere of personal behavior, while necessary, creates limited, slow change. We discuss each in turn, below.

\section{Changing personal sphere behaviors}

\subsection{Translating knowledge to behavior}

Knowledge does not easily translate to action [11]. Humans, while clever and evolutionarily successful, face certain limitations, both cognitive and social [12], that prevent agile and appropriate response to a crisis such as climate change.

Just like any other member of an ecosystem, human beings are constantly responding to information from their environment. Cues from the world around us steadily shape our actions - we grab a raincoat in response to rain, or close the window to shut out the neighbor's music. The cues we receive from climate change have not triggered an immediate response. Climate change, which is all around us and already happening, offers our senses only diffuse signals in our daily lives. Except for the small but growing number of people who have directly experienced a climate-fueled event, the worst consequences of climate change feel distant in space and time, and its connections to everyday experience are complex and understandable

Corresponding author: elamel@,stthomas.edu 
only when translated from science. The slow climatic changes recorded by scientists over the previous 100 years tend to be a dry and cognitive set of events rather than a personal, and emotionally jarring, experience. Without a strong sensory signal, and without an emotional response, we are unlikely to feel moved to action [13].

The conveniences of our modern lives similarly blunt our response to the growing ecological crises we are creating. Where does our food come from? Our water? Our heat and power? For most people in the global north, we are rarely forced to think about the sources or consequences of meeting our daily needs. This leaves us ignorant and confused about our interdependencies, and blind to the damages being done to resources we depend upon [14]. Despite being deeply embedded in nature for most of human history, several hundred years of philosophical and scientific thought have created both a physical and an emotional separation between humans and the rest of nature [15]. Of course, we are $100 \%$ dependent upon planetary resources, not only for our individual needs, but also to run our constructed economies (see Fig. 1) [16]. Yet because we do not perceive these dependencies directly in our day to day lives, issues that threaten human well-being, such as climate change, aquifer depletion, or species loss, do not attract our immediate attention.

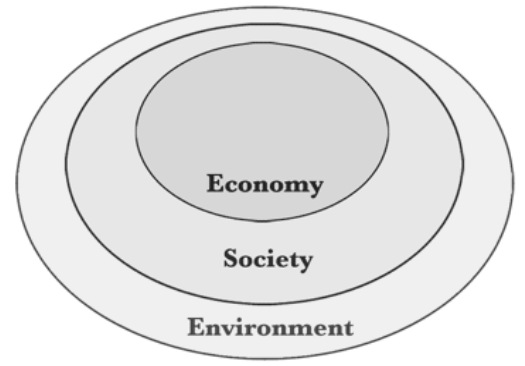

Fig. 1. Nested dependencies model of sustainability implies society and economy are dependent on the environment.

In addition to a sense of separation, modern western science and culture encourage worldviews that reject or ignore these human-planet interdependencies [17]. Worldviews are a set of beliefs about how the world works; they develop over time and experience. Western, industrial worldviews came into being in an era when planetary resources seemed inexhaustible and there were fewer people on the earth. The belief that clean air and water and a stable climate are endless has not caught up with the environmental realities that we are now facing (see Fig. 2).

Our social worlds also play a role in our response to climate change and other forms of environmental damage. Human beings are social creatures; our species survived because we cooperated with and depended upon others. Evolution has thus honed our awareness of social signals. We unconsciously seek reassurance that we are accepted by others, we conform our behavior to group expectations, and we discard behaviors that draw disapproval of others $[6,18]$. Unfortunately, in many communities, the norm continues to be a consumer-driven, waste-generating, $\mathrm{CO} 2$-intensive lifestyle. Even those members of the community who are uncomfortable with the social and environmental implications of this norm may feel uncomfortable openly questioning it for fear of offending friends, neighbors, family members.

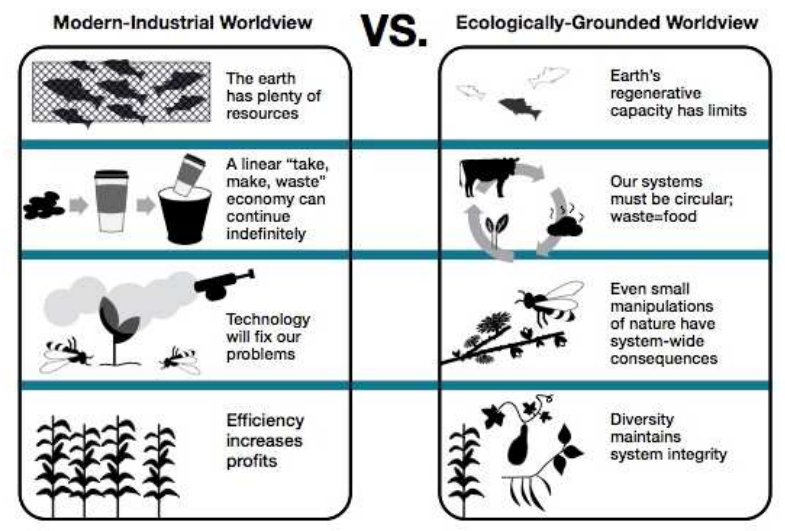

Fig 2. Comparison of assumptions based on two worldviews.

In fact, the data show that a majority of people are concerned about the impact of their lifestyles, and most are willing to make personal efforts because of that concern [19]. A further barrier to action may be their false perception that they are alone in their concern; they are unaware that others share their beliefs and their willingness to act. This mistaken perception of being the only one is called pluralistic ignorance, and in the U.S. it appears to perpetuate the status quo of not dealing with climate change [20].

\subsection{Working against systems}

Even if one overcomes these perceptual, emotional, belief-driven, and social barriers, behavior change may not ensue. In many cases, individual action is simply no match for the large systems we have built for energy, transportation, and agriculture [21]. We build oil pipelines and then ask people to conserve. We design car-centric roads and then expect people to walk and bike along them. We subsidize global, monoculture crops and then ask individuals to eat local at a higher financial cost. Changing behavior is hard under even in supportive circumstances; it is especially difficult when you must work against giant systems and infrastructure that render your actions costly, dangerous, impossible, or meaningless [22].

Working against large systems is cognitively punishing as well. Behaving in an ecologically compatible way requires conscious intentions and deliberate actions, both of which use extensive cognitive resources. The underlying challenge is that we generally attempt to reserve our effortful thinking for emergencies - some researchers have actually called us "cognitive misers." Whenever we have to look harder for an alternative or conduct a background investigation for a choice we want to make, it quickly becomes overwhelming and exhausting. 


\subsection{The limited impact of private sphere action}

While we certainly need people to choose walking, biking and taking public transit instead of driving solo in automobiles, these private-sphere, individual-level actions are not enough. Even if many individuals make high-impact choices like eliminating flying or deciding not to have children [23], we will not achieve the changes in impact needed to drastically reduce greenhouse gas emissions in the next 12 years [24]. The power of the individual to mitigate environmental harm is severely inhibited by the larger infrastructure through which we grow and transport food, generate energy, and produce goods. Not only do these systems lock individuals into resource-intensive behavior patterns, such as car-centric, suburban living and eating food produced by industrial agriculture, they also generate enormous damage on their own. For example, a 2017 study found that $70 \%$ of global greenhouse gas emissions were emitted by a group of approximately 100 corporations, among them many fossil fuel companies [25]. Private sphere individual change cannot undo that $70 \%$.

Another danger of encouraging people to engage in individual-level action is the "single action bias" [13]. This is the tendency for people to engage in just one single behavior change, even when a larger set of actions are available and advisable. It seems that taking any action at all results in a feeling of relief or accomplishment that reduces the need for further change. Given this, we should prioritize actions that have the largest potential for impact, such as collective actions in the public and the organizational spheres.

\section{Moving from individual to collective action}

Individual action is not limited to the personal sphere (see Figure 3). Individuals can participate in collective efforts to pull the social, political, and organizational levers which drive system transformation. These system transformations will in turn drive collective sustainable behavior in a far more efficient way.

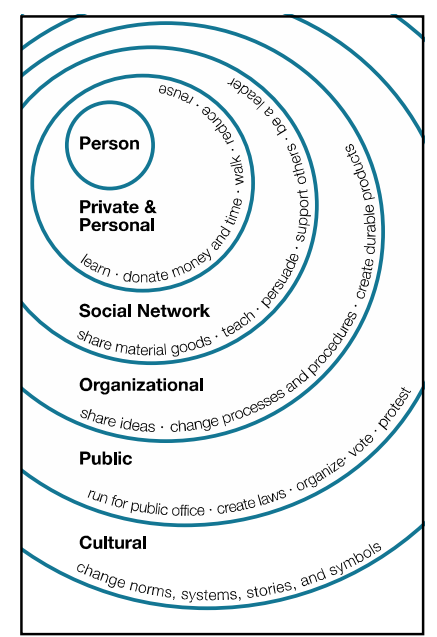

Fig. 3 Taxonomy of individual behaviors that have incrementally magnified effects.

\subsection{Social networks}

One lever of collective change is a person's social network. Every individual has the potential to be a node of transformation within their community, to model a new behavior, offer support to others, and share ideas and resources. The Diffusion of Innovation model [26] suggests that change moves through a social network beginning with visionary individuals willing to try something bold and new, such as joining a community solar garden or participating in a climate march. According to the model, once these early adopters are noticed by opinion leaders, a charismatic group of people with large networks of "followers", a tipping point is reached and the "bold and new" behavior quickly becomes mainstream. Of course, not every individual has connections to powerful opinion leaders, but they can shift their personal social network through their own bold action.

\subsection{Political action}

Individuals can also focus their actions on political change. At the most basic level, citizens can use their right to vote, and they can contact their elected representatives to demand policy change. Activism is also a behavior change option, but one that pushes many individual out of their comfort zone. Speaking at a public forum, publishing an opinion piece, or attending a rally or demonstration are all ways to move beyond individual-action and push for policy changes [27]. Evidence suggests that people are more likely to participate in activism if they believe the political action is necessary, it will impact other people, and it has the potential to change outcomes [28].

\subsection{Organizational behavior}

Finally, individuals can create systems change by pushing organizations to shift their policies and practices. As already noted, formal organizations such as corporations, non-profits, boards, churches and governments have an enormous environmental impact. Formal organizations, particularly corporations, also wield power in determining environmental and labor policy at all levels of government in many parts of the world, particularly the U.S. [29]. When an organization aligns its dealings with sustainability, it has direct positive environmental and social justice benefits. When many organizations move toward sustainability, the policy landscape will shift.

Though it may seem a daunting or impossible task for an individual to exert influence upon an organization, particularly a formal organization such as a corporation, it is important to remember that organizations are social collectives, and like any other type of social collective, are made up of individual people. Though the power structures and rules of an organization may limit a particular individual's ability to formally initiate organizational change, any individual member of an organization can have an 
impact through their connections to others, both formal organizational relationships and informal social relationships. Their efforts to foster change toward sustainability will be noted by, and influence, these connections. As organizational visionaries or early adopters, their efforts have the potential to catch on and move the whole collective toward sustainability. More realistically, any individual who speaks out in the service of sustainability dispels pluralistic ignorance and makes it easier for others to speak and act more openly about their concerns.

Of course, formal leaders within an organization have much more power to successfully move an organization toward environmental and socially responsible policies. Much is known about formal leadership [30] and, specifically, successful leadership in the face of crisis [31]. A particularly potent form of influence during crises, and thus particularly appropriate for the magnitude and speed of change needed to deal with our environmental challenges, is transformational leadership [32]. Transformational leaders are known to influence people in ways that help them refocus attention, reprioritize tasks, and persevere in the face of adversity. Transformational leaders are trusted by others because they have clear expertise yet they make others feel important too. Such leaders energize and empower others to take on risks and to overcome challenges (see Fig. 4). It may seem like a rare individual who can pull off this kind of leadership, but in fact, transformational leadership skills are learnable, particularly if we pay attention to those who model them [33].

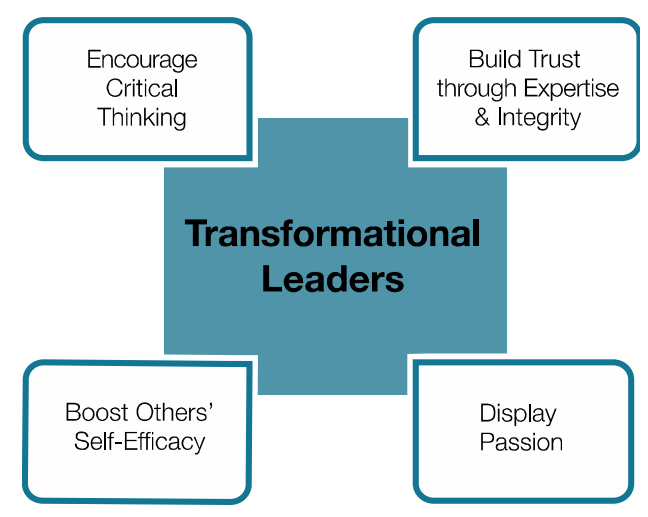

Fig. 4 Combination of actions typical of transformational leaders.

Organizations provide unique contextual factors in the form of norms, institutional values, policy, tasks, pressure from constituencies, and leader involvement that drive human actions and behavior change [34]. For instance, organizations regularly use a variety of tools to communicate explicitly and implicitly about group norms and expectations. Because formal organizations directly employ much of the world's adult population, they have the capacity to move large numbers of people in new directions through work rules, regulations, and workplace culture [31]. Communicating to new members about "how we do things around here," helps them fit in but also helps them work more effectively [35]. When "how we do things around here" becomes sustainable, the cultural shift creates a strong lever for organizations to design better processes, products, energy sources, and services.

Organizational culture can also be influenced by individuals outside the organization. Organizations care about their reputations, and will change practices when pressured by enough public outcry. Individuals can also push organizational change by encouraging and supporting others - neighbors, friends, or family members within powerful organizations - to be part of a movement for change.

\section{Conclusion}

Whether the focus is on mitigating further deterioration of our climate or adapting to the consequences of damage already done, changing human behavior is essential. We cannot underestimate the social, cognitive and systemic challenges to individual human behavior change, however, we have a robust set of psychological tools to guide our way forward in more effective ways [36]. Yet, the domain of choice for behavior change must turn to the systems level. Individuals can and must learn, model, and encourage others within their spheres of influence to make difficult, significant choices that change whole organizations, be they informal neighborhood groups or established corporations. Our future depends on it.

\section{References}

1. S. Capstick, I. Lorenzoni, A. Corner, L. Whitmarsh,Carbon Manage. 5, 429-445 (2015).

2. S. Nicholson-Cole, Sci Commun. 30, 355-379 (2009).

3. D.M. Kahan, H. Jenkins-Smith, D. Braman, J. Risk Res. 14, 147-174 (2011).

4. D.M. Kahan, E. Peters, M. Wittlin, P. Slovic, L.L. Ouellette, D. Braman, G. Mandel, Nat. Clim. Change 2, 732-735 (2012).

5. A.M. Bliuc, C, McGarty, E.F. Thomas, G. Lala, M. Berndsen, R. Misajon, Nat. Clim. Change 5, 226-229 (2015).

6. R. Cialdini, N.J. Goldstein, Annu. Rev. Psychol. 55, 591-621 (2004).

7. L. Whitmarsh, J. Environ. Psychol. 29, 13-23 (2009).

8. A. Leiserowitz, E. Maibach, S. Rosenthal, J. Kotcher, M. Ballew, M. Goldberg, A. Gustafson, Climate change in the American mind: December 2018. (Yale Program on Climate Change Communication, New Haven, CT, 2018).

9. A. Leiserowitz, E. Maibach, S. Rosenthal, J. Kotcher, M. Goldberg, M. Ballew, A. Gustafson, P. Bergquist, Politics \& Global Warming, December 2018. Yale Program on Climate Change Communication, New Haven, CT, 2019).

10. K. O'Brien, E. Selboe, B.M. Hayward, Ecol. Soc. 23, 42 (2018). 
11. R. Gifford, Am. Psychol. 66, 290 (2011).

12. J. Cinner, Science, 362, 889-890 (2018) .

13. E.U. Weber, Climatic Change 77, 103-120 (2006)

14. P. Frank, C. Brock, Psychol. Market. 35, 586-602. (2018).

15. B.A. Scott, E.L. Amel, S.M.Koger, C.M. Manning, Psychology for Sustainability (Routledge, New York, $4^{\text {th }}$ edition, 2016). Chapter 2.

16. B. Giddings, B. Hopwood, G. O'Brien, Sustain. Dev. 10, 187-196 (2002).

17. R.E. Dunlap, K.D. Van Liere, A.G. Mertig, R.E. Jones, J. Soc. Issues, 56, 425-442 (2000).

18. J.W. Bolderdijk, P.K. Lehman, E.S. Geller, "Encouraging Pro-Environmental Behaviour with Rewards and Penalties," in Environmental Psychology: An Introduction, L. Steg, J.I.M. DeGroot, Eds. (Wiley, Hoboken, NJ, 2018), 273282.

19. Pew Research Center, The Politics of Climate [Online].

Available: http://www.pewresearch.org/science/2016/10/04/th e-politics-of-climate/ [Access date: 4 October 2016].

20. N. Geiger, J. K. Swim, J. Environ. Psychol. 47, 79-90 (2016).

21. T. Jackson, "The challenge of Sustainable Lifestyles," in State of the World 2008, G. Gardner T. Prugh, Eds. (WorldWatch Institute, Washington, DC, 2008), chap 4.

22. E. Shove, Environ. Plann. 42, 1273-1285 (2010).

23. S. Wynes, K.A. Nicholas, Environ. Res. Lett. 12, 074024 (2017).

24. IPCC, Global Warming of $1.5^{\circ} \mathrm{C}$, MassonDelmotte, V., P. Zhai, H.-O. Pörtner, D. Roberts, J. Skea, P.R. Shukla, A. Pirani, Moufouma-Okia, C. Péan, R. Pidcock, S. Connors, J.B.R. Matthews, Y. Chen, X. Zhou, M.I. Gomis, E. Lonnoy, Maycock, M. Tignor, and T. Waterfield, Eds. (World Meteorological Organization, Geneva, Switzerland, 2018).

25. P. Griffin, The Carbon Majors Report Database: CDP Carbon Majors Report 2017 (Climate Accountability Institute, 2017).

26. E. M. Rogers, Diffusion of Innovations (Simon \& Schuster, New York, ed. 4, 1962/2010).

27. H.Han, C. Barnett-Loro, Front. Commun. 3, 55 (2018).

28. C. Roser-Renouf, E. W. Maibach, A. Leiserowitz, X. Zhao, Climatic Change 125, 163-178 (2014).

29. M.E. Kraft, S. Kamieniecki, S., Eds. Business and Environmental Policy: Corporate Interests in the American Political System. (MIT Press, Cambridge, MA, 2007).

30. B.J. Avolio, Full range leadership development (Sage, 2011).

31. E. Van Velsor, L. Quinn, "Leadership and Environmental Sustainability" in Managing Human Resources for Environmental Sustainability, S. E. Jackson, D. S. Ones, S. Dilchert, Eds. (Jossey-Bass, Somerset, US, 2012), chap. 10.
32. B.M. Bass, R.E. Riggio, Transformational leadership (Psychology Press, 2006).

33. J.L. Robertson, J. Barling, J. Organ. Behav. 34, 176- 194 (2013).

34. Y. Inoue, P. Alfaro-Barrantes, Bus. Soc. Rev. 120, 137-160 (2015).

35. T.Galpin, J.L. Whittington, G. Bell, Corp. Gov.: Int. J. Bus. Soc. 15 (2015).

36. S. Clayton, P. Devine-Wright, P.C. Stern, L. Whitmarsh, A. Carrico, L. Steg, J. Swim, M. Bonnes, Nat. Clim. Change 5, 640-646 (2015). 